\title{
Segmental Priapism
}

\begin{tabular}{|l|l|l|}
\hline M. & & Borrelli \\
\hline S. & & Glina \\
\hline E.R. & & Wroclawski \\
\hline J.C. & & Celestino \\
\hline G.M. & Menezes & de Goes \\
\hline
\end{tabular}

\section{Department of Urology, Hospital das Clinicas, University of São Paulo, Brazil}

\section{Abstract}

A case report of a 27-year-old male with segmental priapism of the left proximal corpus cavernosum is presented. Treatment consisted in evacuation and irrigation of the corpus.

Dr. Sidney Glina, Departamento de Urologia, Hospital das Clinicas, Universidade de São Paulo, Caixa Postal 8091, BR05403 São Paulo (Brazil)

Segmental priapism is a condition in which a portion of one or both corpora cavernosa is engorged with stagnant blood. This engorgement is frequently prolonged, painful, and not associated with sexual arousal. It is a rare problem, only 4 cases were reported previously. It is important to recognize this entity, differentiating it from other serious problems such as periurethral abscess, infected urethral diverticulum, or metastatic carcinoma.

body. This area then became flaccid. The corpus cavernosum was irrigated with a large bore needle using normal saline until bright red blood drained from the incision. The tunica albuginca then was closed with interrupted chromic sutures and the remainder of the incision closed in a similar fashion.

Postoperatively, the patient felt well and was discharged 5 days later. He was seen periodically in the clinic for the following year and at his last visit was completely normal, sexually potent and had no further perineal pain.

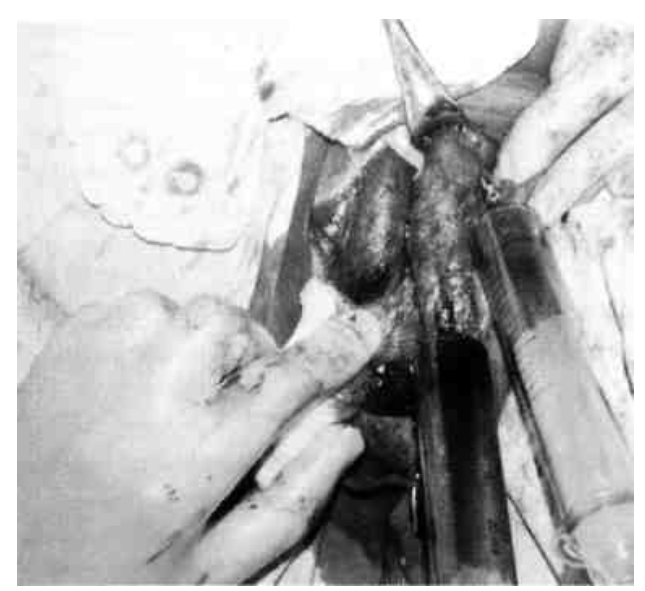

Case Report 
A 27-year-old white man was admitted to the hospital complaining of perineal pain of 4 days duration. He had no previous history of trauma nor did he have difficulty with either urination or erection.

Physical examination revealed a firm, painful perineal mass in the area of the left proximal corpus cavernosum. The remainder of the physical examination including rectal and prostatic examination was entirely normal. Urine analysis was unremarkable as were blood count, coagulation profile, and hemoglobin electrophoresis. Intravenous pyelography and cystourethrography revealed no abnormalities. Because of the persistent painful mass in the perineum, the patient was operated upon through a midline perineal incision. The left, proximal corpus cavernosum was noted to be quite thickened and dark in color. The remainder of the corpus cavernosum was normal. Needle aspiration of the indurated area revealed dark blood without clots. Upon aspiration of the distal corpus, bright red blood was obtained (fig. 1). The indurated portion of the corpus was incised and approximately $20 \mathrm{~cm} 3$ of dark blood was evacuated from the cavernous

Fig. 1. The aspiration of the indurated proximal corpus revealed dark blood. Upon aspiration of the distal corpus, bright red blood was obtained.

Segmental Priapism

157

\section{Comments}

References

Segmental priapism was first reported by Hillis and Weens in 1976 [1]. Since then, 4 other cases have been reported [2-4]. The main feature of this clinical entity is the presence of a hard, painful perineal mass. The etiology of this segmental engorgement of the corpus is unknown. A connective tissue 'septum' has been described between the normal corpus and the more proximal fixed portion which is engorged [1, 3]. This engorgement may occur following vigorous sexual activity [2-4]. Johnson and Corriere [3] thought that local trauma and subsequent thrombosis of the vascular spaces could cause this problem.

In the present case, simple incision and irrigation led to a successful result. Llado et al. [4] reported recurrence after this form of treatment, their patient finally needing a cavernousspongiosum shunt. Those patients that have been reported have retained their sexual potency even after the mass has been present for as long as 2 weeks [ $1,3,4]$. It is speculative as to whether, with nonoperative treatment, this localized corporal engorgement would or would not eventually lead to permanent erectile difficulties. It is important to make the diagnosis, differentiating it from other, more serious lesions.

Hillis, R.S.; Weems, W.L.: Priapism: an unusual presentation. J. Urol. 116: 124(1976).

Gottesman, J.E.: Recurrent partial priapism. Urology 7; 519 (1976).

Johnson, G.R.; Corriere, J.N., Jr.: Partial priapism. J. Urol. 123: 779 (1980).

Llado, J.; Peterson, L.J.; Fair, W.R.: Priapism of the proximal penis. J. Urol. 123: 779 (1980). 